\title{
A CRÍTICA DA FENOMENOLOGIA DE HUSSERL À VISÃO POSITIVISTA NAS CIÊNCIAS HUMANAS
}

\author{
The Critique of Husserl's Phenomenology the Positivist View in Humanities \\ La Crítica de la Fenomenología de Husserl la Visión Positivista en Humanidades
}

Carlos Diógenes CoRTes Tourinho

\begin{abstract}
Resumo: O artigo concentra-se em torno da especificidade da atitude fenomenológica, bem como da metodologia adotada pela fenomenologia de Edmund Husserl no começo do século XX. Tal atitude consiste em uma atitude reflexiva e analítica, a partir da qual se busca fundamentalmente elucidar, determinar e distinguir o sentido íntimo das coisas. Já o método fenomenológico é, por sua vez, um método de evidenciação dos fenômenos, cuja estratégia consiste no exercício da suspensão de juízo em relação à posição de existência das coisas, viabilizando a recuperação destas em sua pura significação. Contrastando a atitude fenomenológica com o que Husserl chamou de "atitude natural" (atitude na qual se encontra mergulhada a consciência das ciências positivas), o artigo abordará, em seguida, a crítica da fenomenologia à perspectiva positivista nas Ciências Humanas.
\end{abstract}

Palavras-chave: Fenomenologia; Ciências humanas; Edmund Husserl; Positivismo.

Abstract: The present paper focuses around the specificity of the phenomenological attitude and the methodological strategy adopted by the phenomenology of Edmund Husserl in the Twentieth Century. Such attitude is reflective and analitical, from which one seeks to fundamentally elucidate, identify and distinguish the sense of things. Impelled by the slogan of the "return to the things itself", the phenomenology of Husserl adopts, through a methodological point of view, the call "phenomenological reduction", that is, the suspension of the judgement in relation to the natural world, to recover it, in the consciousness, in an indubitable way, in his pure meaning. Contrasting the attitude phenomenological with what Husserl called "natural attitude", the paper addressed then the critique of phenomenology to perspective positivist in humanities.

Keywords: Phenomenology; Humanities; Edmund Husserl; Positivism.

Resumen: El presente artículo tiene como objetivo abordar la especificidad de la actitud fenomenológica, así como de la metodología adoptada por la fenomenología de Edmund Husserl a principios del siglo XX. Esta actitud consiste en una actitud reflexiva y analítica, de la cual se busca aclarar, identificar y distinguir el significado íntimo de las cosas. El método fenomenológico es un método de aclaración de los fenómenos, cuya estrategia consiste en el ejercicio de la suspensión del juicio en relación la posición de la existencia de las cosas, lo que permite la recuperación de estos en su significación pura. Por último, se abordará la crítica de la fenomenología la concepción positivista de las humanidades.

Palabras-clave: Fenomenología; Humanidades; Edmund Husserl; Positivismo.

\section{Introdução}

O presente artigo concentra-se em torno da tarefa de aclarar a especificidade da atitude fenomenológica (enquanto modo de consideração do mundo), bem como da metodologia adotada pela fenomenologia de Edmund Husserl para o alcance de um grau máximo de evidenciação dos fenômenos. Tal atitude consiste, conforme será destacado - em uma atitude reflexiva e analítica, a partir da qual se busca, nos termos das "Cinco Lições" de Husserl - em fundamentalmente elucidar, determinar e distinguir o sentido íntimo das coisas (a coisa em sua “doação originária”, revelada "em pessoa”). Já o método fenomenológico será, por sua vez, um método de evidenciação dos fenômenos, cuja estratégia consiste, grosso modo, no exercício da suspensão de juízo em relação à posição de existência das coisas, viabilizando a recuperação destas em sua pura significação.
Contrastando a atitude fenomenológica com o que Husserl chamou de "atitude natural" (modo de orientação no qual se encontra mergulhada a consciência das ciências positivas), o artigo abordará, em seguida, a crítica da fenomenologia à perspectiva positivista nas Ciências Humanas. Enquanto o programa positivista deixa-nos, para o estudo do homem, confinados, do ponto de vista metodológico, a uma lógica indutiva, segundo a qual conhecer consiste em descrever, pela observação positiva dos fatos, a regularidade desses fatos, a abordagem fenomenológica nas ciências humanas convida-nos para uma clarificação do que há de mais fundamental na coisa sobre a qual retornamos, deslocando-nos a atenção dos fatos contingentes para o seu sentido originário indissociável de uma intencionalidade. Tal abordagem consolida, com isso, uma espécie de "conversão filosófica" que nos faz passar de uma visão ingênua do mundo para um modo de consideração das coisas, no qual o mundo se revela em sua totalidade como "fenômeno". 


\section{Atitude Fenomenológica e o Método de Evidencia- ção na Fenomenologia}

Movido por seu projeto filosófico, Husserl anuncia-nos explicitamente - em A Idéia da Fenomenologia (Die Idee der Phänomenologie), núcleo das "Cinco Lições" proferidas em abril-maio de 1907 - que, com a fenomenologia, deparamo-nos com a proposta de uma "nova atitude" e de um "novo método". Deparamo-nos primeiramente com uma ciência, com uma conexão de disciplinas científicas. Mas, para Husserl, acima de tudo, por "fenomenologia" designamos “...um método e uma atitude de pensamento: a atitude de pensamento especificamente filosófica e o método especificamente filosófico" (Husserl, 1907/1997, p. 45).

A atitude fenomenológica consiste em uma atitude reflexiva e analítica, a partir da qual se busca fundamentalmente elucidar, determinar e distinguir o sentido íntimo das coisas, a coisa em sua "doação originária", tal como se mostra à consciência. Trata-se de descrevê-la enquanto objeto de pensamento. Analisar o seu sentido atualizado no ato de pensar, explicitando intuitivamente as significações que se encontram ali virtualmente implicadas em cogitos inatuais, bem como os seus diferentes modos de aparecimento na própria consciência intencional. Explorar a riqueza deste universo de significações que a coisa - enquanto um cogitatum - nos revela no ato intencional é o que é próprio da atitude fenomenológica enquanto um "discernimento reflexivo" levado a cabo com rigor.

A especificidade de tal atitude faz da fenomenologia a "ciência clarificadora" por excelência. Já o método fenomenológico será, por sua vez, um método de evidenciação plena dos fenômenos. Também será, para Husserl, o método especificamente filosófico, cuja estratégia maior consiste, para o alcance de um grau máximo de evidência, no exercício da suspensão de juízo em relação à posição de existência das coisas. Tal exercício viabiliza, assim, a chamada "redução fenomenológica" e, com ela, a recuperação das coisas em sua pura significação, tal como se revelam (ou se mostram), enquanto objetos de pensamento, na consciência intencional.

O ponto de partida de Husserl é o que ele próprio definiu, no § 27 de Idéias I, como sendo a "Tese do Mundo" (ou mais precisamente, a "Tese da Orientação Natural"), isto é, a tese segundo a qual o que chamamos de "mundo" encontra-se aí, diante de nós, tudo isto que, da maneira a mais imediata e direta, nos é revelado através da experiência sensível: as coisas situadas em uma dimensão espaço-temporal, cada uma das quais com as suas propriedades, relações, etc. Trata-se do mundo que nos cerca, constituído de entes mundanos, frente aos quais podemos tomar atitudes variadas, quer nos ocupemos com eles quer não. Vivenciamos, portanto, a todo instante, a chamada "Tese do Mundo". Mas, se além da vivência dessa tese, fazemos uso da mesma, passamos, en- tão, a exercer o que Husserl chamou de "atitude natural" (natürliche Einstellung).

$\mathrm{Na}$ atitude natural, atribuo a mim um corpo em meio a outros corpos e me insiro no mundo através da experiência sensível. Admito, em tal atitude, sem que haja, ao menos, um exame crítico, a existência do mundo (concebido como "realidade factual"), bem como a possibilidade de conhecê-lo e, com isso, adoto, de certo modo, um "realismo ingênuo". Daí Husserl afirmar, em seu importante artigo de 1911, intitulado A filosofia como ciência rigorosa, que: "Toda ciência da natureza se comporta de maneira ingênua...a natureza tomada como objeto de suas investigações encontra-se para ela simplesmente aí" (Husserl, 1911/1989, p. 25).

Neste sentido, a tarefa crítica da Teoria do Conhecimento de promover uma investigação acerca do que torna possível a relação de correspondência entre as vivências cognoscitivas e as coisas a serem conhecidas encontra-se desapercebida na atitude natural. Dá-se às costas para o chamado "enigma do conhecimento transcendente", para o que, classicamente, passou-se a chamar pelo nome de "problema da correspondência". Afinal, o que torna possível tal conhecimento do mundo? Em que ele se funda? Quais são os seus limites? "Como pode o conhecimento estar certo da sua consonância com as coisas que existem em si, de as 'atingir'?' (Husserl, 1907/1997, p. 103). Dá-se, portanto, na atitude natural, a possibilidade do conhecimento do mundo (entendido como "realidade factual") como algo certo e inquestionável. Nos termos de Husserl: "Óbvia é, para o pensamento natural, a possibilidade do conhecimento...não há nenhum ensejo para lançar a questão da possibilidade do conhecimento em geral" (Husserl, 1907/1997, p. 41). Para Husserl, tanto a consciência do senso comum quanto a consciência das ciências ditas "positivas" encontram-se, ainda que de modos distintos, mergulhadas na atitude natural, cujo exercício expressa a relação entre uma consciência espontânea (empírica ou psicológica) e o mundo natural, revelado empiricamente para essa consciência em sua facticidade. Absorvida por esse realismo ingênuo, tal consciência natural - tanto do senso comum quanto das ciências positivas - não se aperceberá do enigma do conhecimento transcendente em torno do qual gira a tarefa crítica da investigação promovida pela Teoria do Conhecimento: afinal, "como pode o conhecimento ir além de si mesmo, como pode ele atingir um ser que não se encontra no âmbito da consciência?" (Husserl, 1907/1997, p. 105).

Para Husserl, se torna obscuro como pode o conhecimento atingir o que é transcendente, aquilo que não é, em seus termos, dado em pessoa, mas "trans-intentado". Porém, nas "Cinco Lições", Husserl alerta-nos para o fato de que se o conhecimento encerra um problema, não significa dizer, com isso, que ele seja em si próprio problemático. Em outros termos, admitir que haja no conhecimento um enigma, não nos obriga a afirmar que todo o conhecimento é enigmático. Husserl deixa-nos claro en- 
tão que, na esfera do conhecimento objetivo, aquilo que é enigmático, que nos deixa perplexos sobre a possibilidade de conhecer é propriamente a sua "transcendência". Tal constatação coloca-nos, conforme veremos mais adiante, frente a relação entre mundo interior e mundo exterior, entre o "imanente" e o "transcendente".

Fiel ao seu projeto filosófico de constituição da filosofia como uma "Ciência de Rigor", Husserl sabe que as tais evidências apodíticas - necessárias para a fundamentação da própria filosofia - não poderiam ser extraídas do plano empírico-natural, pois, por mais perfeita que seja uma percepção empírica, ela será sempre a percepção de um ponto de vista e, enquanto tal, somente poderá revelar "aspectos" ou "perspectivas" - admiravelmente convergentes, mas continuamente diversas e incompletas - da coisa percebida (perceptum) que, por sua vez, não será revelada em sua plenitude, mas apenas parcialmente, "por um de seus lados". Ainda assim, a crença acerca do que percebemos empiricamente vai muito além daquilo que a percepção empírica efetivamente nos revela. Neste sentido, pode-se dizer que a coisa vista empiricamente será sempre um "misto de visto e não visto". Portanto, toda evidência extraída do plano empírico-natural, no qual a consciência empírica se relaciona com as coisas mundanas, será sempre uma evidência perspectivista (ou existencial), ou seja, uma evidência parcial.

Dos fatos não podemos extrair "evidências absolutas". A coisa e o mundo em geral não são apodíticos, pois não excluem a possibilidade de que duvidemos deles e, portanto, não excluem a possibilidade de sua não existência. Eis um segundo motivo do porque não podermos, na visão de Husserl, extrair evidências plenas de nossa percepção empírica do mundo, pois, a julgar pelo o que a experiência sensível nos revela do mundo, nós jamais poderíamos eliminar, por completo, a possibilidade de duvidar da posição de existência das coisas que se nos apresentam e, neste sentido, estaríamos sempre prestes a corrigir as nossas percepções do que havia sido estabelecido com base na experiência sensível. "É sempre possível que o curso ulterior da experiência nos obrigue a abandonar o que já se tinha estabelecido sob a autoridade da experiência" (Husserl, 1913/1950, p. 150). Portanto, para Husserl, com base no ente mundano, seria impossível elaborar uma filosofia que se pudesse apresentar como ciência rigorosa.

Com vistas a viabilizar tal projeto filosófico, surgia, então, para Husserl, o desafio de encontrar uma estratégia metodológica que renunciasse, sem negar a existência do mundo tal como um cético, ao modo de consideração do senso comum e das ciências positivas acerca do mundo, modo esse ingênuo e espontâneo por meio do qual as coisas somente se revelariam, conforme vimos, parcialmente. Em outros termos, o desafio de Husserl consistiria em encontrar um método cujo exercício tornasse viável uma operação capaz de garantir o aparecimento das coisas em sua "inteireza”, em sua doação originária, revelando-se na consciência em uma evidenciação plena ou "apodítica”.
Afinal, conforme ficará cada vez mais claro, tudo aquilo que não tiver o caráter de apresentação imediata, só realizável na consciência, não pode ser "apodítico".

Husserl opta, então, como estratégia metodológica para o alcance das evidências apodíticas, pelo exercício da epoché, isto é, pelo exercício da "suspensão de juízo" em relação à posição de existência das coisas. Husserl recupera, já nas “Cinco Lições” e, posteriormente, em Idéias I, o conceito de epoché do ceticismo antigo, porém, para pensá-lo não como um modus vivendi (como um princípio ético a ser praticado como "hábito virtuoso") - conforme propunha o ceticismo pirrônico no período Helênico mas sim, como um recurso metodológico. Com o exercício da epoché, abstemo-nos de tecer considerações acerca da existência ou não existência das coisas mundanas. Nos termos de Husserl, promovo a "colocação da atitude natural entre parênteses", a facticidade do mundo fica "fora de circuito" (Husserl, 1913/1950, p. 96). Ao suspender o juízo em relação à facticidade do mundo, eu não deixo de vivenciar a "tese do mundo", no entanto, como diz o § 31 de Idéias I, não faço mais uso dessa tese, procuro mantê-la fora de circuito: “.... tese é um vivido, mas dele não fazemos 'nenhum uso'...” (Husserl, 1913/1950, p. 99). Tal renúncia implica, de certo modo, em uma espécie de “conversão filosófica”, por meio da qual adotamos um novo modo de consideração do mundo.

A serviço desta tal reflexividade radical própria da atitude fenomenológica, a epoché fenomenológica - enquanto um "instrumento de depuração do fenômeno" - proporcionará, em seu exercício generalizado, o deslocamento da atenção, inicialmente voltada para os fatos contingentes do mundo natural, para o domínio de uma subjetividade transcendental, “...domínio absolutamente autônomo do ser puramente subjetivo...” (Husserl, 1924/1970, p. 321), dentro da qual e a partir da qual os "fenômenos" - enquanto idealidades puras - se revelarão como "evidências absolutas" para uma consciência transcendental, dotada da capacidade de ver verdadeiramente estes fenômenos tal como se apresentam em sua plena evidência. Trata-se, como o próprio Husserl insiste em ressaltar, em diferentes momentos de sua obra, de um "puro ver" (reinen Schauen) das coisas. Ainda nos termos do § 35 de Idéias I, trata-se “...não exatamente e meramente do olhar físico, mas do 'olhar do espírito'...” (Husserl, 1913/1950, p. 113). Nas "Cinco Lições”, Husserl nos diz: "A fenomenologia procede elucidando visualmente, determinando e distinguindo o sentido...Mas tudo no puro ver" (Husserl, 1907/1997, p. 87). Em suma, a fenomenologia prescindirá de tecer considerações acerca da posição de existência das coisas mundanas para direcionar, então, a atenção para os "fenômenos", tal como se revelam (ou como se mostram), em sua pureza irrefutável, na autoreflexão da consciência transcendental. Nos termos de Husserl, atingimos assim o "ego cogito" verdadeiramente radical, somente inteligível na sua explicitação plena "ego-cogito-cogitatum". 
Portanto, de um lado, deparamo-nos com um modo de consideração das coisas a partir do qual o mundo se revela para a nossa consciência espontânea como o domínio empírico-natural dos fatos, do que se encontra submetido a uma dimensão espaço-temporal. Trata-se do modo de consideração do mundo próprio das ciências positivas em geral. Paralelamente, como um recurso metodológico para o alcance das evidências apodíticas, o exercício generalizado da epoché e, conseqüentemente, da redução fenomenológica, promoverá o salto para o modo de consideração transcendental (ou fenomenológico) das coisas, fazendo agora com que o mundo se revele, na e para a consciência pura (ou transcendental), como um "horizonte de sentidos”. Se esta consciência pura não pode ser tomada em termos de dados empíricos, cabe-nos apenas concebê-la a partir de sua relação intencional com o seu objeto que, em sua versão reduzida, enquanto um objeto de pensamento, nada mais é do que um conteúdo intencional da consciência.

Trata-se, com tal redução, de fazer o mundo reaparecer na consciência como um horizonte de idealidades meramente significativas, que se revelam como um dado absoluto e imediato para uma tal consciência pura que o apreende e o constitui intuitivamente. A mesma consciência que intuitivamente apreende o objeto em sua versão reduzida, isto é, como "fenômeno puro", é também responsável pela constituição desse mesmo objeto, agora atualizado no pensamento como uma unidade de sentido. O objeto, precisamente porque inconcebível sem ser pensado, enquanto um cogitatum, exige uma doação de sentido que só pode vir através dos atos intencionais da consciência, isto é, as unidades de sentido pressupõem uma consciência doadora de sentido. Sendo assim, dizer que toda consciência é consciência de alguma coisa é dizer que não há cogito sem cogitatum.

Portanto, deparamo-nos com duas atitudes - a "atitude natural" e a "atitude fenomenológica" - que, por sua vez, colocam-nos frente a frente com o que Husserl considerou, no $§ 76$ de Idéias I, a mais radical de todas as diferenciações ontológicas: o ser como ser "transcendente" e o ser como consciência, ou ser transcendental (Husserl, 1913/1950, p. 243). Tais atitudes consistem em duas orientações ou dois modos distintos de consideração das coisas. Na primeira dessas orientações, o mundo exterior que transcende a consciência, mundo para o qual nos encontramos naturalmente orientados, nos é revelado em sua facticidade (em termos tomistas, diríamos sob o modo de existência de "coisa natural"/ esse naturale). Eis a idéia do ser como "ser transcendente", fora da consciência. Já na orientação fenomenológica, o mundo se revela, na autêntica imanência da consciência transcendental, em sua pura significação, o que é o mesmo que dizer que o mundo se revela, em sua totalidade, como "fenômeno" (como um dado imanente), inexistindo sob o modo de "coisa pensada" (cogitatum) na consciência. As referidas atitudes impõe-nos, portanto, respectivamente, duas modalidades radicais de ser: o ser como "transcendente" e o ser como consciência (ou ser transcendental). A fenomenologia transcendental será, então, uma fenomenologia da consciência constituinte (pode-se dizer que, em Husserl, "ser evidente é ser constituído”). Exercer a epoché é reduzir à consciência transcendental. Tal redução do objeto à consciência transcendental, na medida em que não desfaz a relação entre sujeito e objeto, revela uma dimensão nova dessa relação, impedindo que a verdadeira e autêntica objetividade desapareça.

\section{A Crítica da Fenomenologia às Ciências Positivas}

Quando pensamos a crítica da fenomenologia às ciências positivas, pensamos, então, em dois modos distintos de consideração do mundo. Tal crítica se faz notar, particularmente, quando pensamos a relação da fenomenologia com as ciências humanas. Para Husserl, não podemos inferir, como pretendem as correntes positivistas, uma lei geral a partir da observação de casos particulares e da constatação de sua regularidade (afinal, dos fatos não podemos extrair "evidências absolutas", a coisa e o mundo em geral não são apodíticos). Com a fenomenologia, deparamo-nos, de antemão, com uma eidética, isto é, com uma "doutrina de essências". Nos termos de Husserl: “...a fenomenologia pode, enquanto ciência, não ser senão uma investigação de essências...” (Husserl, 1911/1989, p. 53). Para Husserl, não há ciência que não comece por estabelecer um quadro de essências obtidas pela técnica de variação imaginária dos objetos. Antes de se fazer física, faz-se necessário refletir sobre o que seja o "fato físico" em sua essência. O próprio Husserl salienta, em sua Crise das Ciências Européias, que Galileu já havia estabelecido uma eidética da coisa física, de modo que não poderia obter a lei da queda dos corpos induzindo o universal a partir do diverso da experiência, mas somente pela "intuição de essência" do corpo físico. O mesmo valeria para as demais ciências. Da definição do eidos apreendido pela intuição originária, se poderá tirar as conclusões metodológicas que orientarão a pesquisa empírica. A cada ciência empírica corresponde uma ciência eidética concernente ao eidos regional dos objetos adotados para investigação (na física, uma eidética da "coisa física"; na psicologia, uma eidética do "fato psicológico", e assim por diante).

A "essência" deve ser entendida em Husserl não como a essência de uma "forma pura" que subsiste por si mesma (tal como em um realismo platônico), independentemente do modo como se mostra à consciência intencional, mas sim como aquilo que é retido no ato intencional desta consciência por meio da redução fenomenológica. Pode-se entender esta essência como aquilo que é retido no pensamento pela técnica de variação imaginária dos objetos: atenho-me, ao exercer a redução fenomenológi- 
ca, ao núcleo invariante da coisa, isto é, ao que persiste na coisa pensada mesmo diante de todas as variações as quais a submeto arbitrariamente em minha imaginação ${ }^{1}$. A variação arbitrária de um objeto qualquer na imaginação permite-nos notar que tal arbitrariedade não pode ser completa, uma vez que há condições necessárias sem as quais as "variações" deixam de ser variações daquilo que se intenciona no pensamento. Cada uma dessas possibilidades ou desses "exemplares" que se perfilam - “...de uma maneira inteiramente livre, ao sabor da nossa fantasia...” (Husserl, 1931, p. 59) - na imaginação somente poderá variar enquanto variação daquilo que se intenciona em um cogito atual, na medida em que necessariamente tais variações compartilham algo de "invariante", coincidindo em relação ao caráter necessário do que é intencionado no próprio pensamento. Nos termos de Husserl, no § 98 de Lógica Formal e Lógica Transcendental, tratam-se de "divergências que se prestam à coincidência" (Husserl, 1929/1965, p. 332). Trata-se, portanto, de uma "condição necessária” sem a qual não poderíamos exercer as referidas variações, sem a qual sequer poderíamos considerar no pensamento um determinado objeto intencionado como tal. Tal "núcleo invariante" do cogitatum - o caráter necessário do objeto idealmente considerado - define precisamente a "essência" (o que Husserl chama, no § 98 da referida obra, de "forma ôntica essencial" ou "forma apriórica” (Husserl, 1929/1965, p. 332) daquilo que se mostra na e para a consciência intencional, revelando-se, portanto, em sua dimensão originária na própria intuição vivida. Eis o que Husserl denominou de "intuição de essências" (Wesenschau). No § 34 de Meditações Cartesianas, Husserl descreve-nos novamente a dinâmica do exercício da variação imaginária dos objetos na consciência, afirmando-nos que tal exercício permite-nos deslocar a atenção das variações as quais submeto arbitrariamente o objeto intencionado para a sua "generalidade essencial" e absoluta, generalidade essencialmente necessária para qualquer caso particular desse mesmo objeto (Husserl, 1931, § 34, pp. 59/60).

Tal modo de conhecimento se torna uma peça decisiva em uma abordagem fenomenológica das ciências do homem. Adotando, por exemplo, tal abordagem na sociologia, se quisermos estudar a existência de uma instituição em um determinado grupo social, sua gênese histórica e o seu papel atual na sociedade, faz-se necessário definir, primeiramente, pela variação imaginária, o que seja esta instituição. Se tomarmos a sociologia de Durkheim como exemplo, constataremos que a mesma assimila a vida religiosa à experiência do sagrado, afirmando-nos que o sagrado tem a sua origem no totemismo, cuja origem resulta, por sua vez, de uma sublimação

\footnotetext{
$\overline{1}$ Husserl menciona-nos a técnica de variação imaginária dos objetos na consciência em alguns momentos de sua obra. Sobre a referida técnica, o leitor poderá consultar (Logique Formelle et Logique Transcendantale, § 98, p. 332; Méditations Cartésiennes, $\S 34$, pp. 59/60).
}

do social. No entanto, é exatamente neste ponto que uma visada fenomenológica da sociologia poderia promover os seguintes questionamentos: a experiência do sagrado constitui a essência da vida religiosa? Não seria possível conceber (por variações imaginárias) uma religião que não se apoiasse sobre esta prática do sagrado? Enfim, o que significa o "sagrado" propriamente dito? Ao invés de inferir leis gerais a partir da observação de casos particulares e da descrição da regularidade desses casos, conforme propõe, do ponto de vista metodológico, o programa positivista, a atitude fenomenológica concentra-se - em um processo inverso aquele adotado pelas ciências positivas - na descrição (ou análise) de essências. Nos termos de Husserl, trata-se, com a atitude fenomenológica, de um processo dinâmico, de uma atitude reflexiva e analítica, cujo intuito central passa a ser o de promover a elucidação do sentido originário que a coisa expressa, em sua versão reduzida, independentemente da sua posição de existência.

Engana-se aquele que pensa que, com a estratégia metodológica adotada pela fenomenologia, Husserl estaria negando a existência do mundo. Antes sim, estaria renunciando a um modo ingênuo de consideração do mesmo, para viabilizar, com o exercício da redução fenomenológica, o acesso a um modo transcendental de consideração do mundo. Em sua versão reduzida, o mundo se abriria, então, enquanto campo fenomenal, na e para a consciência intencional como um "horizonte de sentidos". Sem negar a existência do mundo factual, renunciamos, pela epoché, à ingenuidade da atitude natural, para reter, então, a "alma do mundo", o mundo na sua pura significação. A redução fenomenológica faz reaparecer, na própria camada intencional do vivido, a verdadeira objetividade pela qual o objeto intencionado é, enquanto conteúdo intencional do pensamento, constituído e apreendido intuitivamente. Daí o próprio Husserl dizer que se por "positivismo" entendemos o esforço de fundar as ciências sobre o que é suscetível de ser conhecido de modo originário, nós é quem somos os verdadeiros positivistas! (Husserl, 1913/1950, p. 29). Se as ciências positivas não deixam de conceber a relação entre subjetivo e objetivo em termos da dicotomia "interioridade" / "exterioridade", considerando o objetivo como algo que nos remete sempre para uma realidade exterior e independente, para o que transcende a própria "vivência do mundo", a redução fenomenológica permite-nos, ao nos lançar para o modo transcendental de consideração do mundo, recuperar a autêntica objetividade na própria subjetividade transcendental - domínio último e apoditicamente certo sobre o qual deve ser, segundo Husserl, fundada toda e qualquer filosofia radical - unindo, com isso, o objetivo e o subjetivo. Trata-se, nos termos de Husserl, de "...uma exterioridade objetiva na pura interioridade" (Husserl, 1929/1992, p. 11), trata-se de uma "autêntica objetividade imanente". 


\section{Considerações Finais}

A adoção do programa positivista nas ciências humanas implica, ao fazer uso da Tese do Mundo, ao mergulhar a consciência na atitude natural, na aceitação de um realismo ingênuo, desconsiderando, neste sentido, os problemas filosóficos suscitados pela Teoria do Conhecimento. Este mesmo programa insiste, nos estudos sobre o homem (seja em Sociologia, seja em Psicologia), em extrair leis universais a partir da observação sistematizada do comportamento humano, desenvolvendo um estudo periférico do homem em relação ao meio no qual se insere. Particularmente, em Psicologia, a aceitação do programa positivista começa a se consolidar no último quarto do século XIX por meio de uma aliança da ciência psicológica com o método experimental das ciências naturais. Tal aliança fez, no mesmo período, com que os sistemas em psicologia confundissem, muitas das vezes, na aceitação de um paralelismo psicofísico, as leis do pensamento com as leis causais da natureza, confundindo o "sujeito do conhecimento" com o "sujeito psicológico", conforme o próprio Husserl denunciou em sua crítica ao psicologismo nos Prolegômenos das Investigações Lógicas. Tal programa positivista deixa-nos, para o estudo do homem, confinados, do ponto de vista metodológico, a uma lógica indutiva, segundo a qual conhecer consiste em descrever, pela observação positiva dos fatos, a regularidade desses fatos, buscando, a partir de casos particulares, inferir uma "lei geral". Para Husserl, tal lei inferida nada mais é do que uma "regra empírica", cuja validade é meramente circunstancial e, portanto, uma regra que carece de exatidão absoluta. Ao se lançar sobre os fatos por meio de uma observação sistematizada, no exercício da indução, o positivista desconhece o quadro de essências acerca dos fatos que investiga.

Já a abordagem fenomenológica nas ciências humanas convida-nos a exercer justamente uma reflexividade levada a cabo com rigor e discernimento acerca deste quadro de essências estabelecido por variações imaginárias, a vivência da intuição do que há de originário (ou de invariante) naquilo que se toma como objeto de investigação. Convida-nos a uma atitude reflexiva e analítica acerca do sentido íntimo daquilo que se investiga - tanto aquele que se atualiza no pensamento quanto as significações que se encontram ali virtualmente presentes, bem como os seus diferentes modos de aparecimento na própria camada intencional do vivido. Convida-nos, portanto, para uma clarificação do que há de mais fundamental na coisa sobre a qual retornamos, deslocando- nos a atenção dos fatos contingentes para o seu sentido originário indissociável de uma intencionalidade, consolidando, com isso, uma espécie de "conversão filosófica" que nos faz passar de uma visão ingênua do mundo para o "puro ver" das coisas, no qual o mundo se revela em sua totalidade como "fenômeno". Eis o convite genuíno da fenomenologia às ciências humanas.

\section{Referências}

Husserl, E. (1931). Méditations Cartésiennes. Paris: Librairie Armand Colin.

Husserl, E. (1950). Idées directrices pour une phénoménologie et une philosophie phénoménologique pures (Tome Premier). Paris: Gallimard (Original de 1913).

Husserl, E. (1965). Logique Formelle et Logique Transcendantale. Paris: PUF (Original de 1929).

Husserl, E. (1970). Philosophie première 1923-1924, 1: Histoire critique des idées. Appendice. Paris: PUF (Original de 1924).

Husserl, E. (1989). La philosophie comme science rigoureuse. Paris: PUF (Original de 1911).

Husserl, E. (1992). Conferências de Paris. Lisboa: Edições 70 (Original de 1929).

Husserl, E. (1997). L’idée de la phénoménologie. Cinq leçons. Paris: PUF (Original de 1907).

Carlos Diógenes Côrtes Tourinho - Formado em Psicologia pela Universidade Federal Fluminense e em Filosofia pela Universidade Federal do Rio de Janeiro. Mestre e Doutor em Filosofia pela Pontifícia Universidade Católica do Rio de Janeiro (PUC-RJ). Professor de Filosofia da Faculdade de Educação e do Programa de Pós-graduação em Filosofia da Universidade Federal Fluminense (UFF). Membro do Núcleo de Estudos e Pesquisas em Filosofia, Política e Educação (NUFIPE/ UFF) e dos GTs de Filosofia Francesa Contemporânea e de Fenomenologia da ANPOF. Organizador da Coleção Encontros com a Filosofia (EDUFF/ Booklink) e da Série Ensaios sobre o Pensamento Contemporâneo (Editora Proclama). Recentemente, organizou o primeiro livro do GT de Fenomenologia da ANPOF: Fenomenologia: influxos e dissidências (Booklink, 2011). Endereço Institucional: Universidade Federal Fluminense, Faculdade de Educação/ Departamento de Fundamentos Pedagógicos (SFP). Campus do Gragoatá (São Domingos). CEP 24020200. Rio de Janeiro/RJ. E-mail: cdctourinho@yahoo.com.br

Recebido em 12.07.11 Aceito em 10.12.11 